\title{
Influence of microphysical schemes on atmospheric water in the Weather Research and Forecasting model
}

\author{
F. Cossu ${ }^{1,2}$ and K. Hocke ${ }^{1,2}$ \\ ${ }^{1}$ Institute of Applied Physics, University of Bern, Bern, Switzerland \\ ${ }^{2}$ Oeschger Centre for Climate Change Research, University of Bern, Bern, Switzerland \\ Correspondence to: F. Cossu (federico.cossu@iap.unibe.ch)
}

Received: 20 July 2013 - Published in Geosci. Model Dev. Discuss.: 9 September 2013

Revised: 2 December 2013 - Accepted: 4 December 2013 - Published: 28 January 2014

\begin{abstract}
This study examines how different microphysical parameterization schemes influence orographically induced precipitation and the distributions of hydrometeors and water vapour for midlatitude summer conditions in the Weather Research and Forecasting (WRF) model. A high-resolution two-dimensional idealized simulation is used to assess the differences between the schemes in which a moist air flow is interacting with a bell-shaped $2 \mathrm{~km}$ high mountain. Periodic lateral boundary conditions are chosen to recirculate atmospheric water in the domain. It is found that the 13 selected microphysical schemes conserve the water in the model domain. The gain or loss of water is less than $0.81 \%$ over a simulation time interval of 61 days. The differences of the microphysical schemes in terms of the distributions of water vapour, hydrometeors and accumulated precipitation are presented and discussed. The Kessler scheme, the only scheme without ice-phase processes, shows final values of cloud liquid water 14 times greater than the other schemes. The differences among the other schemes are not as extreme, but still they differ up to $79 \%$ in water vapour, up to 10 times in hydrometeors and up to $64 \%$ in accumulated precipitation at the end of the simulation. The microphysical schemes also differ in the surface evaporation rate. The WRF singlemoment 3-class scheme has the highest surface evaporation rate compensated by the highest precipitation rate. The different distributions of hydrometeors and water vapour of the microphysical schemes induce differences up to $49 \mathrm{~W} \mathrm{~m}^{-2}$ in the downwelling shortwave radiation and up to $33 \mathrm{~W} \mathrm{~m}^{-2}$ in the downwelling longwave radiation.
\end{abstract}

\section{Introduction}

Atmospheric processes that occur at spatial and temporal scales not resolved by global and regional climate models (GCMs and RCMs) are represented by means of physical parameterizations (or schemes) based on several assumptions and approximations. The drawback of using these simplified schemes is the risk of introducing systematic errors, especially when long-term simulations are performed. This study focuses on the microphysical schemes, the parameterizations responsible for computing atmospheric water vapour, cloud liquid water, cloud ice and various types of precipitation. A correct representation of the microphysical processes is crucial for long-term climate simulations. Clouds and water vapour modify the radiative properties of the atmosphere, while precipitation is one of the most important components of the water cycle. Furthermore, microphysics parameterizations affect the hydrological and energy budgets, especially for RCMs that employ mass-conserving formulations of the model equations.

In our study we use the Weather Research and Forecasting (WRF) model (Skamarock et al., 2008), a modern numerical weather prediction (NWP) model. WRF was not designed for long-term climate simulations but it is nonetheless widely used for regional climate downscaling, where the output from a GCM is used to drive a RCM in higher spatial resolution to simulate local conditions in greater detail. A successful example of the use of WRF for regional climate downscaling can be found in Givati et al. (2012), where precipitation amounts simulated with WRF are compared with measurements from a rain gauges network in Israel, showing good agreement. Argüeso et al. (2011) also find positive 
results, concluding that WRF accurately reproduces Andalusian climate features at several timescales. However, such applications have also encountered numerous problems such as strong overprediction (underprediction) of winter precipitation intensity (frequency) (Caldwell et al., 2009), low correlations between modelled and observed daily precipitation over the US Pacific northwest (Zhang et al., 2009), precipitation overestimation over West Africa (Druyan et al., 2009) and excessive rainfall at off-equatorial latitudes and a deficit near the Equator (Tulich et al., 2011).

One of the main reasons for these discrepancies is that different schemes were designed with different conceptual underpinnings and tunable parameters that are not universal and are also quite uncertain. No single scheme performs uniformly well under all conditions, and each has a predictive ability highly dependent on weather or climate regimes (Jankov et al., 2005; Gallus Jr. and Bresch, 2006) and application scales. Furthermore, the model performance often depends on the feedbacks between different schemes.

In order to increase the agreement of the model with available observations, the common practice is to adjust uncertain model parameters manually, often referred to as expert tuning. A different approach towards an objective calibration of RCMs has been recently proposed by Bellprat et al. (2012). Other recent studies focused instead on the systematic development of improved physics representations that are suitable for climate prediction at certain resolutions and presented modified versions of WRF to better suit RCM experiments. One of these, CLWRF (CLimate WRF, Fita et al., 2010), is a set of modifications to the WRF version 3.1.1 code to perform more flexible regional climate simulations. Currently, CLWRF adds three main capabilities to the model: (1) flexible greenhouse gas scenario usage, (2) output of mean and extreme statistics of surface variables and (3) computation of new variables. A similar project, CWRF (Climate WRF, Liang et al., 2012), is a climate extension of WRF that incorporates numerous improvements in the representation of physical processes and integration of external forcings that are crucial to climate scales. This extension inherits all WRF functionalities for NWP while enhancing the capability for climate modelling.

Our objective, rather than developing a new parameterization suitable for RCMs, is to make a comparative evaluation of the existing microphysical schemes available in WRF. Several studies (Jankov et al., 2005, 2009; Otkin and Greenwald, 2008; Mercader et al., 2010; Argüeso et al., 2011; Awan et al., 2011) have assessed WRF microphysical schemes by simulating a real case scenario with multiphysics options and comparing the results with observations. Other studies have used a much simpler setup to investigate the effects of mountain geometry and upstream conditions on orographic precipitation (Chen and Lin, 2005; Miglietta and Rotunno, 2005, 2006; Pathirana et al., 2005; Watson and Lane, 2012), using however only one or two microphysical parameterizations.
The lack of a study which considers more microphysical schemes at the same time and assesses them using a simple scenario has motivated us to perform an idealized simulation with a fixed set of physical schemes and a simple terrain model. Although this method prevents a direct verification with observations and forces the microphysics to interact with a limited number of other physical schemes, it still provides useful information about the range of results that can be obtained using different microphysical schemes.

Our study investigates the effects of the 13 microphysical schemes available in WRF v3.3.1 on orographic precipitation and on the atmospheric water cycle by performing a simple idealized simulation running over a period of two months. In addition, the total conservation of water will be assessed and the influence of the different distributions of atmospheric water on downward radiation at the ground will be analysed.

\section{Simulation setup}

The numerical model chosen for our simulations is the Advanced Research WRF (ARW-WRF, v3.3.1). WRF is a fully compressible and non-hydrostatic model (with a run-time hydrostatic option). Its vertical coordinate is a terrain-following hydrostatic pressure coordinate. The grid staggering is the Arakawa C-grid. The model uses the Runge-Kutta 2nd and 3rd order time integration schemes, and 2nd to 6th order advection schemes in both the horizontal and vertical. It uses a time-split small step for acoustic and gravity wave modes. The dynamics conserves scalar variables. Other information can be found in WRF-ARW user's guide (Wang et al., 2012).

We used a modified version of the test case em_hill2 $d \_x$ which simulates a two-dimensional flow over a bell-shaped mountain. The modifications include simulation duration, epoch, domain size, terrain profile, lateral boundary conditions, initial atmospheric profiles and physical parameterizations.

In order to enhance the differences between the microphysical parameterizations and to allow the system to reach an equilibrium state, we chose a simulation duration of 61 days, running from 1 June 2012, 00:00:00 LT (local time) to 1 August 2012, 00:00:00 LT.

The spatial domain consists of 402 points along $x, 2$ points along $y$ and 41 vertical levels. These are staggered points lying at the interfaces of the Arakawa C-grid cells, therefore the number of mass-points is 401 along $x, 1$ along $y$ and 40 along $z$. The domain is centered on the coordinates $40^{\circ} \mathrm{N}$, $105^{\circ} \mathrm{W}$.

The horizontal resolution is $2 \mathrm{~km}$, while the vertical resolution is variable between $500 \mathrm{~m}$ and $2.3 \mathrm{~km}$, with denser levels near the ground and sparser levels near the model top, which is at $30 \mathrm{~km}$. 


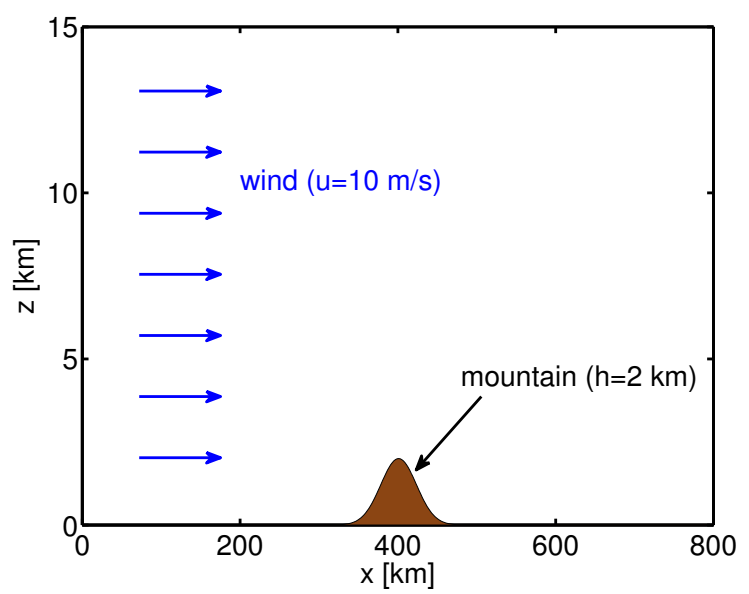

Fig. 1. The terrain profile chosen for our simulations consists of a Gaussian-shaped mountain ridge of $2 \mathrm{~km}$ height and a halfwidth $=\sqrt{\ln 2} a \simeq 27 \mathrm{~km}$ (Eq. 1) centered at $x=401 \mathrm{~km}$. The initial airstream has a uniform speed $u=10 \mathrm{~m} \mathrm{~s}^{-1}$.

The terrain profile, as shown in Fig. 1, was changed according to the following formula:

$h(x)=h_{m} e^{-\left(\frac{x-x_{c}}{a}\right)^{2}}, \quad 1 \mathrm{~km} \leqslant x \leqslant 801 \mathrm{~km}$,

where $h_{m}=2 \mathrm{~km}, a=32 \mathrm{~km}$ and $x_{c}=401 \mathrm{~km}$. This mountain size is high enough to produce orographic precipitation and its low steepness $(\sim 3.75 \%)$ implies that the timescale for the microphysical processes to produce precipitation, which is roughly $20 \mathrm{~min}$ (Miglietta and Rotunno, 2005), is smaller than the typical advective timescale for this simulation $(\sim 45 \mathrm{~min})$.

The initial wind profile has a vertically uniform horizontal component $u=10 \mathrm{~m} \mathrm{~s}^{-1}$ along $x$.

To study the total water budget, we chose periodic lateral boundary conditions so that the air exiting at one side is reinserted at the other side: in this way no water is added to or removed from the system, except for the water vapour added through surface evaporation which can be derived from the latent heat flux at the surface.

The presence of a $2 \mathrm{~km}$-high mountain, besides enhancing precipitation, produces gravity waves in both horizontal and vertical directions. Between 10 and $30 \mathrm{~km}$ altitude, a Rayleigh damping layer absorbs the waves coming from below in order to reduce downward reflection of wave momentum. To diminish the interferences of the horizontal propagating waves, which occur due to the aforementioned boundary conditions, we extended the original domain along $x$ from 400 to $800 \mathrm{~km}$, as described above.

The initial potential temperature profile was computed by averaging an 18 yr-long ECMWF (European Centre for Medium-Range Weather Forecasts )ERA-Interim reanalysis data series for the coordinates $47.25^{\circ} \mathrm{N}, 7.875^{\circ} \mathrm{E}$ (Swiss Plateau) and it is shown in the top panel of Fig. 2. This profile represents fairly well the average midlatitude atmospheric conditions.
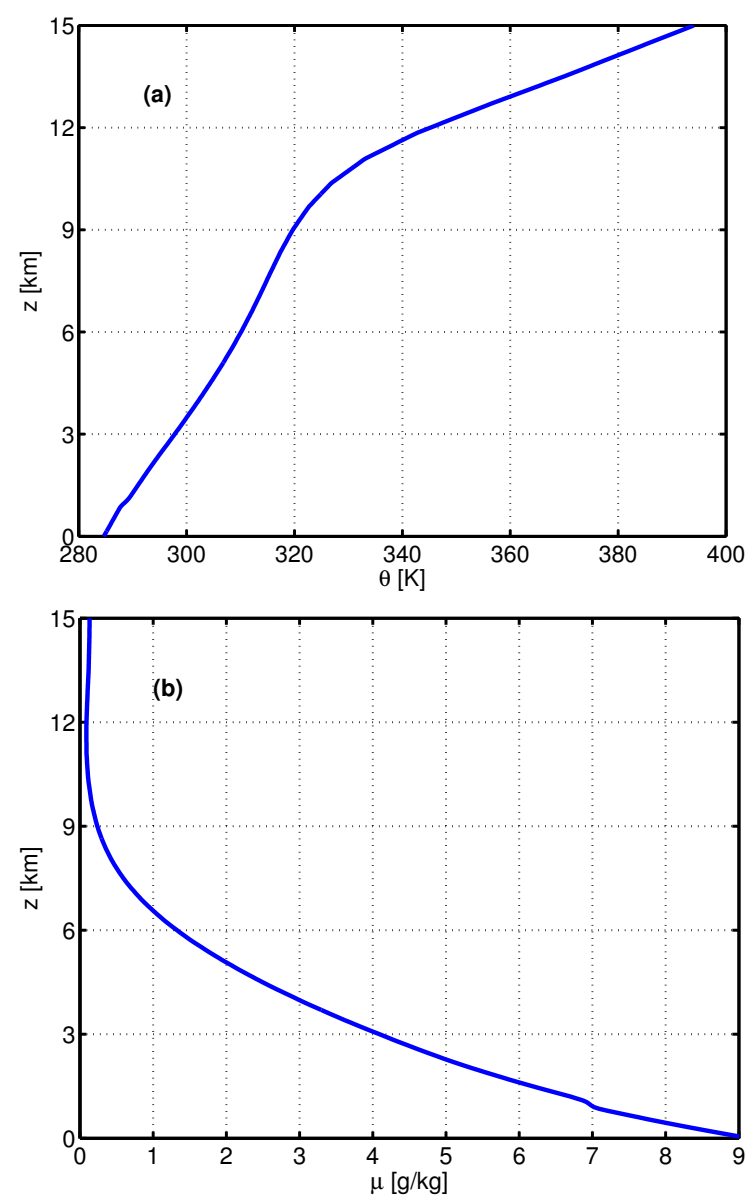

Fig. 2. (a) Initial potential temperature profile computed by averaging an 18 yr-long ECMWF ERA-Interim reanalysis data series for the coordinates $47.25^{\circ} \mathrm{N}, 7.875^{\circ} \mathrm{E}$ (Swiss Plateau), representing typical midlatitude atmospheric conditions. (b) Initial moisture profile corresponding to $100 \% \mathrm{RH}$ (to foster precipitation) based on the potential temperature profile in (a).

For the moisture profile, to foster precipitation, we have chosen a saturated profile computed with the temperature derived from the previous potential temperature profile and by setting the relative humidity to $100 \%$. The resulting profile is shown in the bottom panel of Fig. 2.

The dynamics settings include a 3rd order Runge-Kutta time-integration scheme with a time step of $20 \mathrm{~s}$, a 5 th order scheme for horizontal advection and a 3rd order scheme for vertical advection.

In order to compute the total water budget and to study the effects of atmospheric water on radiation, we had to activate some options of the WRF model. We used the Rapid Radiative Transfer Model scheme for longwave radiation, the Dudhia scheme for shortwave radiation, the MM5 similarity surface layer scheme, the 5-layer thermal diffusion land surface scheme (without snow-cover effects) and the Yonsei University planetary boundary layer scheme. Since the 
Table 1. The microphysical schemes available in WRF v3.3.1. mp_physics is the corresponding option to be used in the configuration file to activate them. The abbreviations are used throughout the whole document to refer to the schemes. The hydrometeors computed by the schemes are v, water vapour; c, cloud water; r, rain; i, cloud ice; s, snow; g, graupel; t, total condensate; and h, hail. The WSM3 scheme also computes cloud ice and snow but includes them in cloud water and rain, respectively.

\begin{tabular}{llll}
\hline mp_physics & Microphysical scheme name & Abbreviation & Hydrometeors \\
\hline 1 & Kessler & KS & v c r \\
2 & Purdue Lin & LN & v c r i g \\
3 & WRF single-moment 3-class & WSM3 & v c r \\
4 & WRF single-moment 5-class & WSM5 & v c r i s \\
5 & Eta microphysics & EM & v c r t \\
6 & WRF single-moment 6-class & WSM6 & v c r i g \\
7 & Goddard microphysics & GM & v c r i g g \\
8 & New Thompson et al. & NT & v c r i s g \\
9 & Milbrandt-Yau double-moment 7-class & MY & v c r i g h \\
10 & Morrison double-moment & MO & v c r i g \\
13 & Stony Brook University (Y. Lin) & SBU & v c r i s \\
14 & WRF double-moment 5-class & WDM5 & v c r i s \\
16 & WRF double-moment 6-class & WDM6 & v c r i g \\
\hline
\end{tabular}

spatio-temporal resolution was high enough to resolve convective processes, we did not use any cumulus parameterization scheme.

The various physics parameterizations interact with each other via the model state variables (potential temperature, moisture, wind, etc.) and their tendencies. At the beginning of the Runge-Kutta time step, the radiation, surface and planetary boundary layer schemes produce tendencies of atmospheric state variables, while the microphysics, being an adjustment process, does not provide tendencies but updates the atmospheric state only at the end of the model time step.

\subsection{Model output}

With this configuration, we ran one simulation for each microphysical scheme available. Table 1 lists the 13 microphysical schemes included in WRF 3.3.1 and the type of hydrometeors they compute. Throughout the document, we will refer to the schemes using the abbreviations listed in this table. We performed a total of 13 simulations and we saved the output every $60 \mathrm{~min}$ for description of the temporal evolution of atmospheric water and accumulated precipitation.

The variables contained in each output file, whose number may vary depending on the type of microphysics selected, provide the user with detailed information about the atmospheric state at specific times. The variables selected in this study for the characterization of the atmospheric water cycle are listed in Table 2 along with their description. Some schemes, due to their lower complexity, lack the computation of some variables. For example, KS lacks the computation of the variables related to ice-phase processes (QICE, QSNOW, QGRAUP and QHAIL). The variables describing water vapour (QVAPOR), cloud water (QCLOUD), rain (QRAIN) and accumulated precipitation (RAINNC) are present in all schemes.

\section{Water conservation}

The water in the domain can be divided into three categories: (A) water vapour, (B) hydrometeors and (C) precipitated water on the ground (see Table 2). The elements from category B can in turn be separated into non-precipitating particles (QCLOUD and QICE) and precipitating particles (QRAIN, QSNOW, QGRAUP and QHAIL). Initially all the water present in the domain is in the vapour phase (QVAPOR, category A). Afterwards water vapour starts to condense into clouds (category B, non-precipitating) and eventually clouds will form precipitation (category B, precipitating), which in turn will increase the amount of water collected at the ground (RAINNC, category C). As the simulation proceeds, each microphysical scheme redistributes the total mass of atmospheric water among the different phases and particles of water.

Water vapour is depleted by condensation, however it can be replenished through evaporation/sublimation of hydrometeors or through surface evaporation. The latter is the most important replenishing mechanism and it is computed by the land-surface model (LSM) in conjunction with the surface layer scheme. The LSM we are using, the 5-layer thermal diffusion, has a fixed soil moisture value, a constant surface temperature profile that depends on terrain elevation and no surface and subsurface runoff (the water that flows over or under the surface when the maximum absorbing capacity of the soil is reached). The constant surface temperature profile is a consequence of the idealized simulation which does not allow the proper initialization of the LSM. Evaporation is always occurring, regardless of the precipitation that falls on the ground, because the soil, modelled with a constant humidity value, is never running out of moisture. The evaporation rate only depends on the properties of the air above 
Table 2. WRF output variables describing the atmospheric water cycle. The variables are divided into three categories whether they represent uncondensed water (A), condensed water particles (B) or precipitated water (C). RAINNC is the sum of all the available types of precipitation that each microphysical scheme is able to compute and might include rain, snow, graupel and hail.

\begin{tabular}{lllcl}
\hline Variable & Units & Description & Category & Type \\
\hline QVAPOR & $\mathrm{kg} \mathrm{kg}^{-1}$ & water vapour mixing ratio & $\mathrm{A}$ & instantaneous \\
QCLOUD & $\mathrm{kg} \mathrm{kg}^{-1}$ & cloud water mixing ratio & $\mathrm{B}$ & instantaneous \\
QRAIN & $\mathrm{kg} \mathrm{kg}^{-1}$ & rain water mixing ratio & $\mathrm{B}$ & instantaneous \\
QICE & $\mathrm{kg} \mathrm{kg}^{-1}$ & ice mixing ratio & $\mathrm{B}$ & instantaneous \\
QSNOW & $\mathrm{kg} \mathrm{kg}^{-1}$ & snow mixing ratio & $\mathrm{B}$ & instantaneous \\
QGRAUP & $\mathrm{kg} \mathrm{kg}^{-1}$ & graupel mixing ratio & $\mathrm{B}$ & instantaneous \\
QHAIL & $\mathrm{kg} \mathrm{kg}^{-1}$ & hail mixing ratio & $\mathrm{B}$ & instantaneous \\
RAINNC & $\mathrm{mm}$ & accumulated total grid-scale precipitation & $\mathrm{C}$ & cumulative \\
\hline
\end{tabular}

the surface (air temperature, air moisture, surface wind) and on the insolation. The water that reaches the surface through precipitation does not take part in the evaporation or in any other process of the water cycle (e.g. runoff). At the sides of the domain water conservation is ensured by the periodic lateral boundary conditions.

To describe the water present in the domain, we use the mean column density of water averaged over the domain, which is measured in $\mathrm{mm}$ or $\mathrm{kg} \mathrm{m}^{-2}$. In the following, we combine the water cycle variables to check if the microphysical schemes of WRF conserve water over a time interval of 61 days. At any time, the total water mean column density $W$ is given by the sum of the water vapour mean column density WV, the hydrometeor mean column density $H$ and the mean accumulated precipitation $P$ :

$W_{t}=W V_{t}+H_{t}+P_{t}$,

where $t$ is the temporal index which goes from $t=0(0 \mathrm{~h})$ to $t=1464$ ( $1464 \mathrm{~h}=61$ days). The single components of this sum are computed as follows:

$$
\begin{aligned}
\mathrm{WV}_{t} & =\sum_{i=1}^{N_{x}} \sum_{k=1}^{N_{z}} \operatorname{QVAPOR}_{i, k, t} \cdot \rho_{i, k, t} \cdot \Delta z_{i, k, t} / N_{x} \\
H_{t} & =\sum_{i=1}^{N_{x}} \sum_{k=1}^{N_{z}}(\mathrm{QCLOUD}+\mathrm{QRAIN}+\mathrm{QICE}+\mathrm{QSNOW} \\
& +\mathrm{QGRAUP}+\mathrm{QHAIL})_{i, k, t} \cdot \rho_{i, k, t} \cdot \Delta z_{i, k, t} / N_{x} \\
P_{t} & =\sum_{i=1}^{N_{x}} \operatorname{RAINNC}_{i, t} / N_{x}
\end{aligned}
$$

where $i, k, N_{x}$ and $N_{z}$ are the indices and the number of cells along $x$ and $z, \rho$ is the air density in $\mathrm{kg} \mathrm{m}^{-3}$ and $\Delta z$ is the height of the cells in $\mathrm{m}$. The meaning of the other variables is explained in Table 2.

$W$ is constantly increasing in time because new water vapour (which was not part of the initial total water) is added to the atmosphere through surface evaporation. If we remove the evaporated water from Eq. (2) we obtain the original total water amount and we are able to check whether this amount remains constant in time or not. When the microphysical schemes convert one type of water particle into another or if a phase transition is involved, some of the water mass could be lost after this conversion. The cause of this water loss could be a numerical truncation error, due to the approximation of the derivatives in the microphysics equations with finite differences, or simply a code bug (new bugs are discovered at every WRF release). By looking at the evolution of the original total water amount we can check to what extent the microphysical schemes conserve water.

The mean accumulated surface evaporation $E$ can be computed with the following formula:

$$
E_{t}=\frac{\sum_{i=1}^{N_{x}} \mathrm{ACLHF}_{i, t}}{L_{\mathrm{v}} \cdot N_{x}},
$$

where ACLHF is the accumulated upward latent heat flux at the surface in $\mathrm{J} \mathrm{m}^{-2}$ and $L_{\mathrm{V}}$ is the specific latent heat of vaporization which is equal to $2.5 \times 10^{6} \mathrm{~J} \mathrm{~kg}^{-1}$.

The original total water mean column density $W_{\text {original }}$ is therefore given by

$W_{\text {original }, t}=W_{t}-E_{t}$.

Figure 3 shows the evolution in time of $W_{\text {original }}$ while Table 3 shows its values at the beginning and at the end of the simulation for the various microphysical schemes. While the initial value of $W_{\text {original }}$ is the same for all schemes $(26.93 \mathrm{~mm})$, its variation is different from scheme to scheme. The small water gains and losses caused by the microphysics add up and at the end of the simulation each scheme presents different values of $W_{\text {original }}$. Only two schemes, MY and MO, have a net gain of water while the other 11 have a net loss.

The rapid variation that most of the schemes exhibit in the first hours is likely due to the model spin-up, after which it is possible to classify them more objectively. MO, starting from day 3 , has a constant water gain with an average rate of $1.55 \times 10^{-3} \mathrm{~mm} \mathrm{day}^{-1}$, while MY has a more random behaviour. Almost symmetrical to MO, KS has a constant water loss (starting at $t=10 \mathrm{~h}$ ) of $-1.67 \times 10^{-3} \mathrm{~mm} \mathrm{day}^{-1}$. Five 
Table 3. The original total water mean column density $W_{\text {original }}$ (see Eq. 7) at $t=0 \mathrm{~h}$ and at $t=61$ days. When the microphysical schemes convert water from one phase into another or one type of particle into another, small water mass gains or losses may occur. The original amount of total water may slightly vary in time, as shown in this table.

\begin{tabular}{lrrrr}
\hline Microphysics scheme & $\begin{array}{r}W_{\text {original }} \\
(t=0 \mathrm{~h}) \\
{[\mathrm{mm}]}\end{array}$ & $\begin{array}{r}W_{\text {original }} \\
(t=61 \text { days }) \\
{[\mathrm{mm}]}\end{array}$ & Absolute difference & Relative difference \\
& 26.93 & 26.81 & -0.12 & {$[\%]$} \\
\hline KS & 26.93 & 26.89 & -0.04 & -0.43 \\
LN & 26.93 & 26.71 & -0.22 & -0.14 \\
WSM3 & 26.93 & 26.71 & -0.22 & -0.80 \\
WSM5 & 26.93 & 26.90 & -0.03 & -0.10 \\
EM & 26.93 & 26.71 & -0.21 & -0.80 \\
WSM6 & 26.93 & 26.88 & -0.04 & -0.16 \\
GM & 26.93 & 26.87 & -0.05 & -0.19 \\
NT & 26.93 & 27.08 & 0.15 & 0.56 \\
MY & 26.93 & 27.03 & 0.11 & 0.39 \\
MO & 26.93 & 26.89 & -0.04 & -0.15 \\
SBU & 26.93 & 26.71 & -0.22 & -0.81 \\
WDM5 & 26.93 & 26.71 & -0.22 & -0.80 \\
WDM6 & & & & \\
\hline
\end{tabular}

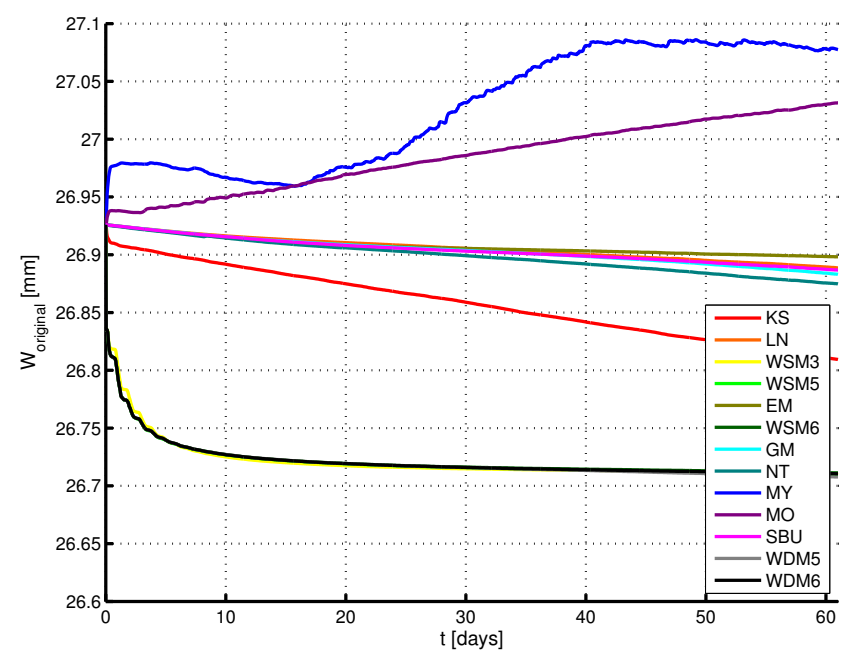

Fig. 3. The original total water mean column density evolution in time for the 13 microphysical schemes. At the beginning of the simulation $W_{\text {original }}=26.93 \mathrm{~mm}$ for all the schemes and then it evolves independently, based on each scheme's microphysical transformations which cause small gains and losses of water during the transitions from one water species/phase into another. The correspondence between the abbreviations in the legend and the names of the schemes can be found in Table 1 .

schemes (LN, EM, GM, NT, SBU) also have a constant water loss, albeit smaller than KS and starting from $t=10 \mathrm{~h}$, between $-0.45 \times 10^{-3}$ and $-0.84 \times 10^{-3} \mathrm{~mm} \mathrm{day}^{-1}$. Lastly, the other five schemes that have a net water loss (WSM3, WSM5, WSM6, WDM5, WDM6) decrease rapidly in the first 4 days and then stabilize towards a final value of about $26.71 \mathrm{~mm}$. The scheme with the smallest total variation is EM with a difference of only $-0.10 \%$ compared to the initial value, while the scheme with the highest variation is WDM5 with a decrease of $-0.81 \%$.

Although the differences in $W_{\text {original }}$ after 61 days are still small both in absolute and relative terms, the schemes with a constant water gain/loss (LN, EM, GM, NT, MO, SBU), if proceeding at the same rate, might reach a non-negligible amount of water gain/loss after a certain time. In a RCM simulation, however, the lateral boundary conditions are not periodic and they are typically updated every 6 or $12 \mathrm{~h}$. The new air mass entering the domain might have much more or much less water vapour than the air mass leaving the domain, leading to a modification of the total water which easily exceeds the rate at which the microphysical schemes change it.

\section{Water cycle components}

The available microphysical schemes range from simple and efficient, to sophisticated and more computationally costly, and from newly developed schemes, to well-tried schemes such as those in current operational models (Wang et al., 2012). Each scheme is therefore able to compute a certain number of variables: for example, the simple KS scheme (Kessler, 1969) considers only water vapour, cloud liquid water and rain, while the more sophisticated LN scheme (Lin et al., 1983) includes also cloud ice, snow and graupel hydrometeors. The number of included microphysical processes and their particular implementation are responsible for the differences derived from the output variables which represent the various components of the water cycle. These differences and the behaviour of the microphysical schemes in the idealized case of orographic precipitation will be quantified and discussed in this section. 


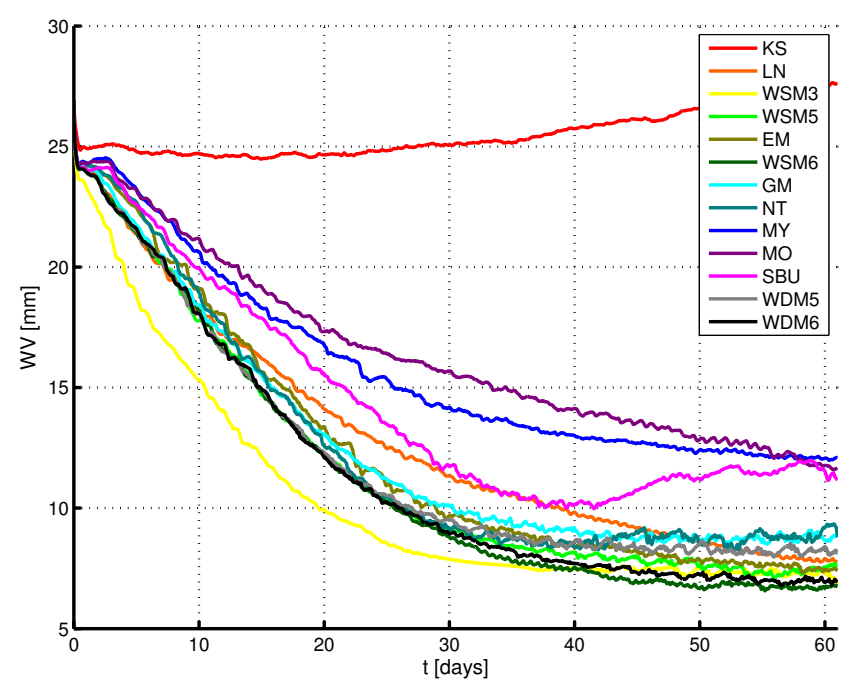

Fig. 4. Comparison of water vapour mean column density for the 13 microphysical schemes. Water vapour is depleted through its conversion into hydrometeors (Fig. 5) and accumulation at the surface under the form of precipitation (Fig. 6).

\subsection{Water vapour}

Figure 4 shows a comparison of WV (Eq. 3) for the 13 microphysical schemes. In the first hours of the simulation, a fast decrease of water vapour is observed for all the schemes, due to the saturated profile chosen for the initialization. In saturated conditions, it is relatively easy for all the schemes to convert water vapour into hydrometeors. This fast decrease could however be caused (entirely or partially) by the model initial spin-up.

During the first few days it is already possible to distinguish different regimes: KS (red line) removes less WV compared to the other schemes and stabilizes at a high value of about $25 \mathrm{~mm}$. WSM3 (yellow line) has an opposite behaviour, removing more WV compared to the other schemes and decreases to values below $10 \mathrm{~mm}$ already on day 20 , while other schemes achieve this value days later and some of them never.

The rest of the schemes are more similar to WSM3 than to $\mathrm{KS}$, in that they progressively remove $\mathrm{WV}$ instead of increasing it. KS, in fact, shows a slight increase in WV over time and its final value $(27.67 \mathrm{~mm})$ is higher than the initial one $(26.93 \mathrm{~mm})$, meaning that the overall water vapour added by surface evaporation was greater than the overall water vapour removed by condensation and precipitation. As opposed to $\mathrm{KS}$, the rate of removal of WV of the other schemes decreases over time (except for SBU, which shows an increase in WV after day 42) and, as long as our simulation period allows us to infer, WV appears to stabilize around the final values listed in Table 4.

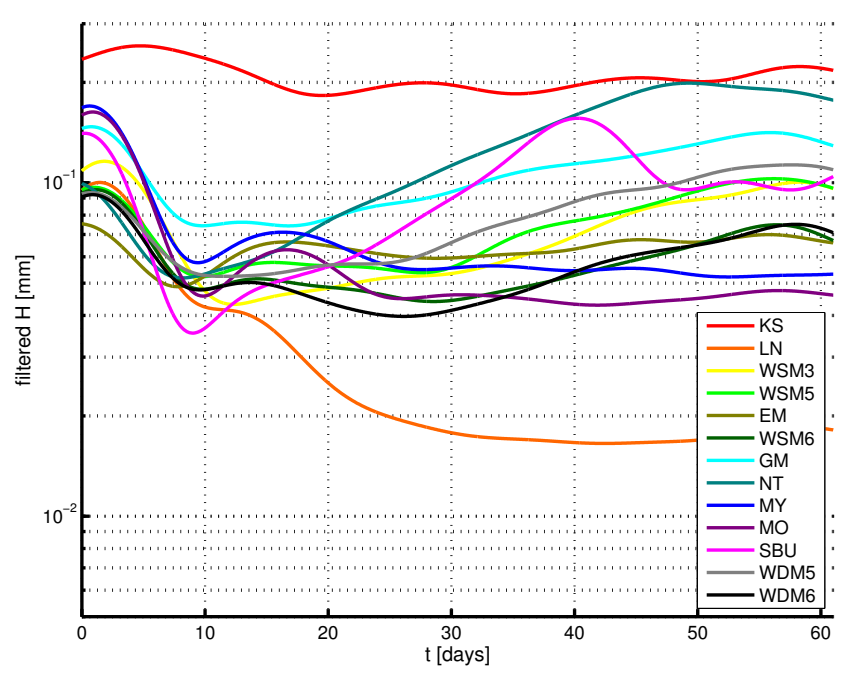

Fig. 5. Comparison of hydrometeor mean column density for the 13 microphysical schemes. To enhance the differences between the schemes, the series have been filtered with a 10-day lowpass filter.

After 61 days all the schemes (except for KS) have lost $55-75 \%$ of their initial water vapour content. Such a big loss can be attributed to the combination of the idealized mountain with the periodic lateral boundary conditions. The flow of moist air is in fact forced to pass several times over the mountain and at every passage orographically induced condensation and precipitation is likely to happen, removing water vapour from the air. The removal of water vapour decreases during the last days because the surface evaporation, by adding new water vapour to the closed system, is finally able to balance the water vapour loss.

\subsection{Hydrometeors}

The hydrometeor mean column density $H$ includes nonprecipitating and precipitating hydrometeors, as already mentioned at the beginning of Sect. 3. Non-precipitating hydrometeors are composed of cloud droplets and ice crystals and their mass mixing ratios are given by the variables QCLOUD and QICE. Precipitating hydrometeors are rain, snow, graupel and hail and their mass mixing ratios are given by the variables QRAIN, QSNOW, QGRAUP and QHAIL. In Eq. (4) these 6 different hydrometeors are summed together to compute $H$.

In the time series of $H$ the differences between the microphysical schemes are hard to see due to the strong hour to hour variability which causes the lines to intersect each other like in a "spaghetti" plot. By using a 10 day lowpass filter it is possible to better visualize the differences between the series, as can be seen in Fig. 5 .

KS exhibits the highest value of $H$ (around $0.2 \mathrm{~mm}$ ), which remains more or less constant in time. KS reaches soon an equilibrium state in which condensation of water 
Table 4. Mean column density values of water vapour WV, hydrometeors $H$, accumulated precipitation $P$ and accumulated evaporation $E$ at the end of the simulation. The initial total water mean column density is $26.93 \mathrm{~mm}$ for all the schemes and it is solely under the form of water vapour. The values of $H$ are from the series filtered with a 10 day lowpass filter and are shown with 3 decimal digits instead of 2 due to the lower magnitude of $H$ compared to the other components of the water cycle. The last column of the table shows the mean residence time of water vapour for the last 10 days of the simulation.

\begin{tabular}{lrrrrr}
\hline Microphysics scheme & $\begin{array}{r}\text { WV } \\
(t=61 \text { days }) \\
{[\mathrm{mm}]}\end{array}$ & $\begin{array}{r}H \\
(t=61 \text { days }) \\
{[\mathrm{mm}]}\end{array}$ & $\begin{array}{r}P \\
(t=61 \text { days }) \\
{[\mathrm{mm}]}\end{array}$ & $\begin{array}{r}E \\
(t=61 \text { days }) \\
{[\mathrm{mm}]}\end{array}$ & $\begin{array}{r}\text { WV residence time } \\
\text { (last 10 days) } \\
\text { [days] }\end{array}$ \\
\hline KS & 27.62 & 0.217 & 11.30 & 12.37 & 271.0 \\
LN & 7.78 & 0.018 & 58.04 & 38.95 & 8.3 \\
WSM3 & 7.03 & 0.096 & 71.65 & 52.04 & 6.3 \\
WSM5 & 7.54 & 0.096 & 65.62 & 46.59 & 6.7 \\
EM & 7.40 & 0.066 & 62.74 & 43.34 & 7.2 \\
WSM6 & 6.75 & 0.067 & 66.68 & 46.80 & 6.2 \\
GM & 8.89 & 0.129 & 62.72 & 44.79 & 8.4 \\
NT & 8.80 & 0.177 & 63.93 & 46.46 & 8.9 \\
MY & 12.10 & 0.053 & 46.56 & 31.62 & 16.6 \\
MO & 11.66 & 0.046 & 43.65 & 28.31 & 16.1 \\
SBU & 11.17 & 0.104 & 49.81 & 34.26 & 16.2 \\
WDM5 & 8.12 & 0.109 & 65.04 & 46.59 & 7.7 \\
WDM6 & 6.93 & 0.071 & 65.71 & 45.99 & 6.4 \\
\hline
\end{tabular}

vapour to create new droplets is balanced by the formation of rain hydrometeors and their removal by surface accumulation, which leads to an almost constant $H$ in time.

For all the other schemes, after the initial overproduction due to the saturated conditions, $H$ is rapidly decreasing until day 10 , after which every scheme follows its own evolution. LN continues to decrease and stabilizes to values just below $0.02 \mathrm{~mm}$, while NT grows rapidly and reaches values similar to KS on day 50. SBU is also characterized by a rapid increase between day 10 and day 40 , then it decreases between day 40 and day 50 and it finally stabilizes at about $0.1 \mathrm{~mm}$ for the last 10 days. The rest of the schemes after day 10 have less marked variations and their values are between 0.04 and $0.1 \mathrm{~mm}$.

The final values of $H$ reached by the schemes are listed in Table 4. The biggest difference is between KS $(0.217 \mathrm{~mm})$ and $\mathrm{LN}(0.018 \mathrm{~mm})$, with KS being 12 times higher than $\mathrm{LN}$. For some schemes, such as KS, LN, MY and MO, these final values might be valid also for the following days, as these schemes seem to have reached an equilibrium state. The rest of the schemes, instead, might need more time to relax towards more stable values.

\subsection{Precipitation}

For all the schemes, the highest precipitation rate occurs during the first day, thanks to the initial high availability of water vapour in the atmosphere. The saturated initial moisture profile causes an overproduction of hydrometeors, as we have seen in the previous section, which sediment to the ground as precipitation. As mentioned before, this initial strong variation could also be a direct consequence of the model spin-up.
The variable in which the accumulated precipitation at the surface is stored is RAINNC and it is averaged along $x$ in Eq. (5) to obtain the mean accumulated precipitation $P$, whose time series is shown in Fig. 6.

For the whole simulation period $\mathrm{KS}$ has the lowest value of $P$ and WSM3 the highest, as opposed to $\mathrm{WV}$, because precipitation is inversely proportional to water vapour. WSM3 reaches a final value of $71.7 \mathrm{~mm}$, more than 6 times higher than KS (Fig. 6a).

The sharp increase of $P$ in the first day observed for all the schemes (Fig. 6b) corresponds to the sharp decrease in WV of Fig. 4. Whether this effect is due to oversaturation or to the model spin-up, it nicely shows the balance of the different components of the water cycle.

After the first day, the mean precipitation rate is reduced for all the schemes and remains more or less constant in time, corresponding to an almost constant slope of the lines in Fig. 6a. Each scheme is therefore accumulating precipitation at its own pace, although there are some schemes which are more closely spaced. WSM5, EM, WSM6, GM, NT, WDM5 and WDM6 have similar values throughout the whole simulation and they reach final values only 7-12\% lower than WSM3. SBU, MY and MO have, instead, smaller final values (30-39\% lower than WSM3) and their lines are more separated from each other. LN has the second highest value of $P$ during the first 10 days, then it decreases considerably and, starting around day 25 , becomes the 9th scheme until the end, with a final value $19 \%$ lower than WSM3. The final values of $P$ are listed in Table 4 . 

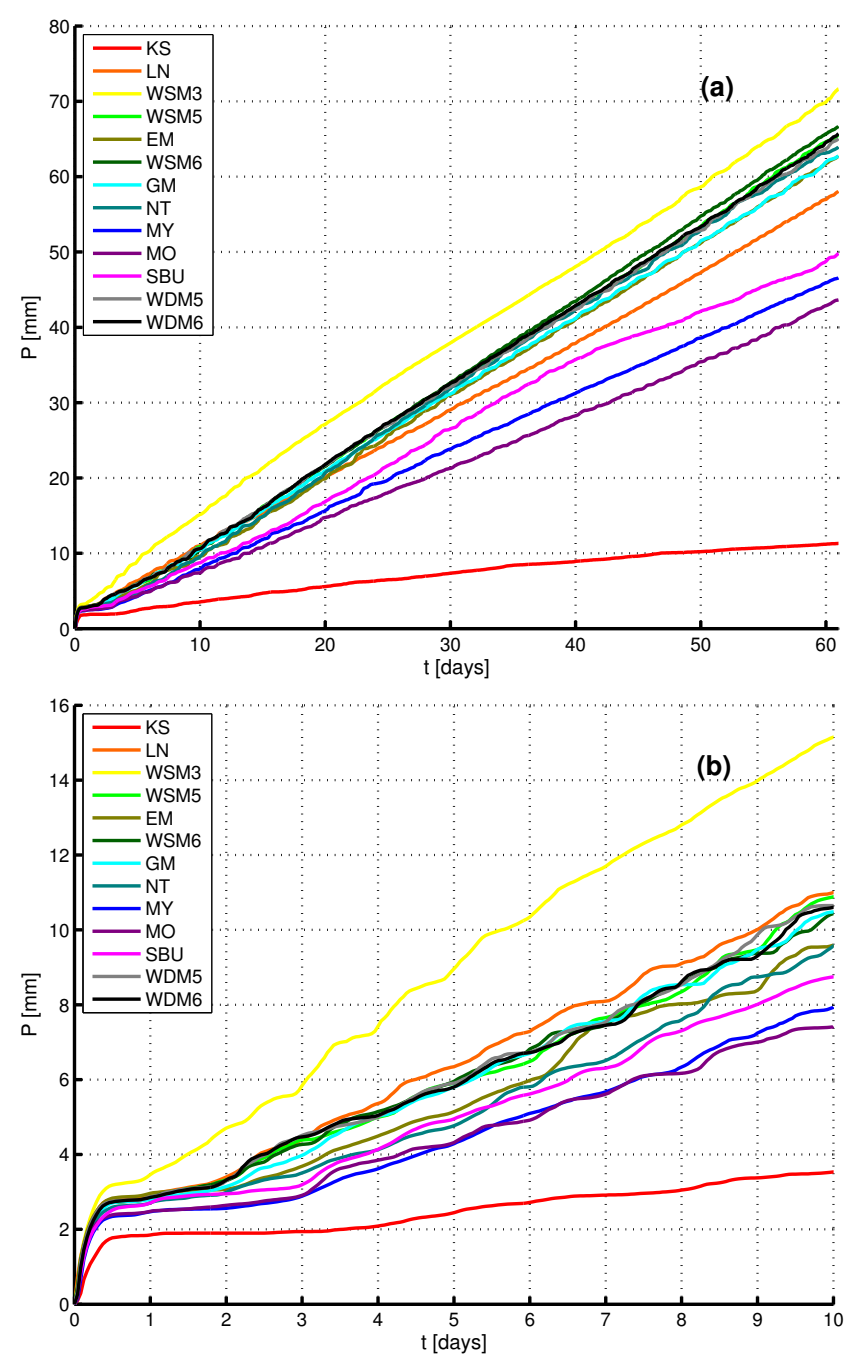

Fig. 6. Comparison of mean accumulated precipitation for the 13 microphysical schemes, in (a) the complete time series and in (b) the zoom over the first 10 days.

Except for KS, all the schemes produce more precipitation than the initial total water mean column density of $26.93 \mathrm{~mm}$ because, aside from the existing initial water vapour, additional water vapour is provided by surface evaporation, as explained in Sect. 3, which is used for further condensation and precipitation.

The excessive production of precipitation in WSM3 is also present in Druyan et al. (2009), who obtained exaggerated precipitation rates over West Africa using this scheme for their RCM simulation. Low precipitation rates for KS are also found in Liang et al. (2002), where KS produces unrealistic low values of precipitation in the simulation of a floodproducing heavy rainfall over the central US.

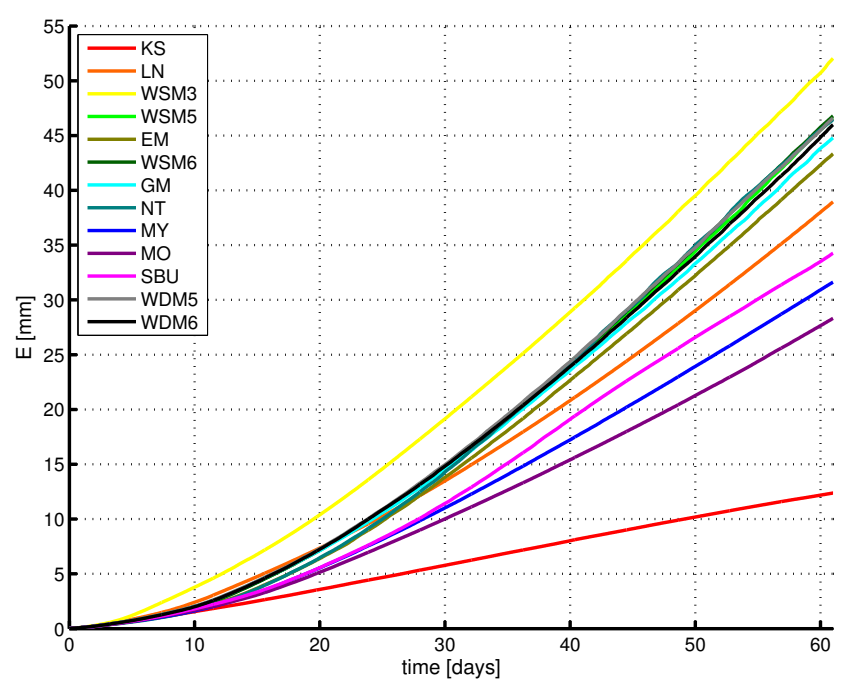

Fig. 7. Comparison of mean accumulated evaporation for the 13 microphysical schemes. The lines seem to follow an exponential increase rather than the linear increase of the lines in Fig. 6a.

\subsection{Evaporation}

The total mean accumulated surface evaporation $E$, shown in Fig. 7, is computed using Eq. (6). In the first day $E$ is very small for all the schemes with similar values below $0.1 \mathrm{~mm}$. After day 1, WSM3 sets itself above the rest of the schemes and continues to grow until the end of the simulation, reaching a final value of $52 \mathrm{~mm}$. KS has again an opposite behaviour compared to WSM3, becoming the scheme with the smallest $E$ starting from day 9 and reaching a final value of only $12.4 \mathrm{~mm}$. A list of the final values of $E$ for all the schemes is provided in Table 4.

Since $E$ represents the accumulated evaporation, its first derivative is the evaporation rate. The slope of the lines is always positive which means that evaporation is continuously occurring during the simulation. Since the surface temperature is prescribed, the water vapour mixing ratio at the lowest model level dominates the surface evaporation: the more the water vapour, the weaker the evaporation, and vice versa. In the first days, in fact, the high concentration of water vapour prevents the water from evaporating from the surface efficiently. Conversely, in the following days, as water vapour is removed from the atmosphere through condensation and precipitation, the evaporation becomes stronger.

The evaporation in our 61 days simulation is needed because without it the atmosphere would be depleted of water vapour very fast, being the mean residence time of water vapour in the terrestrial atmosphere of about 15 days (Chahine, 1992).

For the schemes that reach an almost constant WV (KS in the first 30 days and almost all the other schemes in the last 10 days), there is a balance between precipitation and evaporation: water vapour is removed by precipitation as quickly 


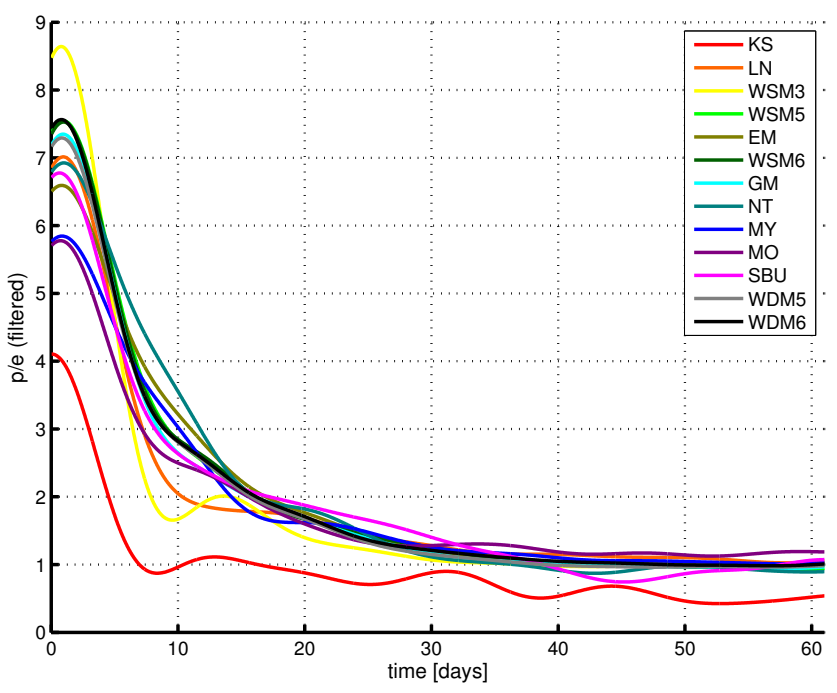

Fig. 8. The ratio between precipitation rate and evaporation rate for the 13 microphysical schemes. The series have been filtered with a 10 day lowpass filter. For $p / e \rightarrow 1$ the closed system reaches its equilibrium.

as it is replaced by evaporation. In this balance $H$ is irrelevant because it is a couple of orders of magnitude smaller than the other quantities in play.

The ratio between precipitation rate and evaporation rate ( $p / e$ ratio) is shown in Fig. 8, in which the series have been filtered with a 10 day lowpass filter. Starting from day 30 , the schemes reach a $p / e$ ratio of about 1 , indicating that the system has reached an equilibrium state. The $p / e$ ratio for $\mathrm{KS}$ is below 1 , meaning that there is a net gain of water vapour, in agreement with the increase of WV in Fig. 4.

The last column of Table 4 lists the mean residence time of water vapour in the last 10 days, computed by dividing the mean WV by the mean precipitation rate. Only three schemes (MY, MO, SBU) have residence times in accordance with Chahine (1992), and, except for KS which has an extremely long residence time of 271 days, all the other schemes have residence times below 9 days, indicating a faster water cycle.

\section{Effects on radiation}

In WRF atmospheric radiation is treated as two separate components, longwave and shortwave. Longwave radiation includes infrared or thermal radiation absorbed and emitted by gases and surfaces. Upward longwave radiative flux from the ground is determined by the surface emissivity that in turn depends upon land-use type, as well as the ground (skin) temperature. Shortwave radiation includes visible and surrounding wavelengths that make up the solar spectrum. Hence, the only source is the Sun, but processes include absorption, reflection, and scattering in the atmosphere and at surfaces. For shortwave radiation, the upward flux is the reflection due to surface albedo. Within the atmosphere the radiation responds to model-predicted cloud and water vapour distributions, as well as specified carbon dioxide, ozone, and (optionally) trace gas concentrations (Skamarock et al., 2008).

Depending on the radiation scheme selected, the number of spectral bands goes from 2 to 16 for longwave radiation and from 1 to 19 for shortwave radiation. In our simulations longwave radiation is parameterized with the Rapid Radiative Transfer Model (RRTM) (Mlawer et al., 1997), a spectral-band scheme using the correlated- $k$ method with 16 different bands covering infrared wavelengths from $3 \mu \mathrm{m}$ to $1 \mathrm{~mm}$. RRTM uses pre-set tables to accurately represent longwave processes due to water vapour, ozone, $\mathrm{CO}_{2}$, and trace gases (if present), as well as accounting for cloud optical depth. The scheme chosen to parameterize shortwave radiation is the MM5 Dudhia scheme (Dudhia, 1989), which has a simple downward integration of solar flux (only one band) and accounts for clear-air scattering, water vapour absorption and cloud reflection and absorption. Absorption by other atmospheric gases is not considered. All clouds and precipitation are treated as one type of cloud. The effects of the solar zenith angle are taken into account, which reduces the downward component and increases the path length.

In this section we focus on the effects of water vapour and clouds on downward radiation at the surface by analysing the output variables GLW and SWDOWN which represent, respectively, the downward longwave and shortwave fluxes at ground surface in $\mathrm{W} \mathrm{m}^{-2}$. The differences between the microphysical schemes are also considered.

\subsection{Longwave radiation}

Longwave radiation emitted from the surface is absorbed and reemitted by greenhouse gases and clouds. In our WRF simulation the upward longwave emission from the surface is computed by the 5-layer thermal diffusion land-surface model, which parameterizes the surface with a constant emissivity and a constant altitude-dependent temperature profile.

The amount of longwave radiation that every greenhouse gas is able to absorb and reemit depends on the local temperature, on its concentration and on the gas itself. Unlike water vapour, whose concentration varies during the simulation, all the other absorbing gases are modelled with a prescribed concentration profile and their contribution to the radiation budget is therefore less variable.

Also hydrometeors can absorb and emit longwave radiation. Particularly, the bottom layers of thick clouds emit downward longwave radiation (DLR) like a grey body radiating at a certain temperature, which usually corresponds to the ambient air temperature, and with a certain emissivity. Even assuming a constant emissivity, the spatio-temporal variability of the cloud distribution yields a very variable DLR at the surface. We should therefore expect a DLR surface flux characterized by two components: a slow-varying component due 


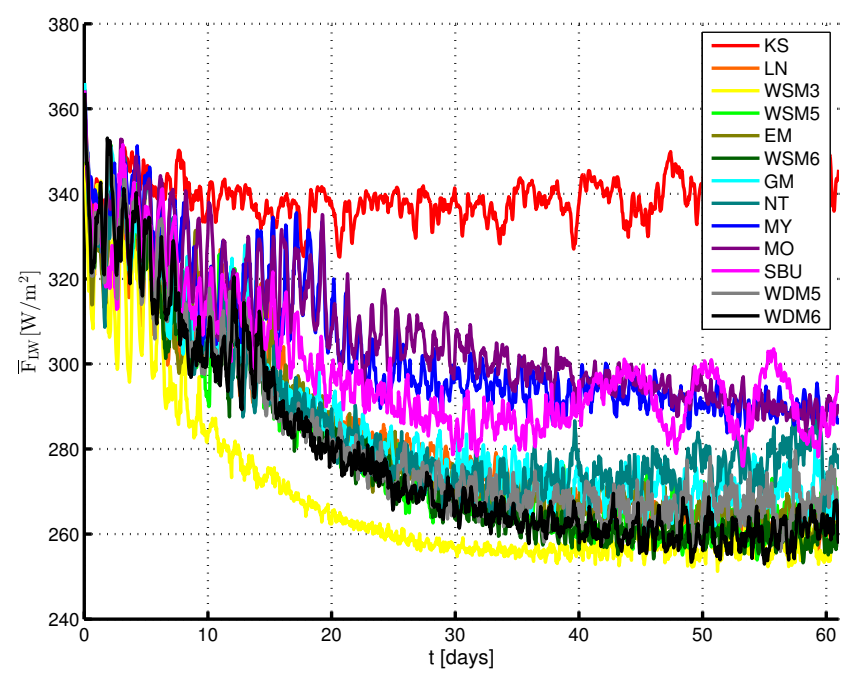

Fig. 9. Comparison of the mean DLR flux at the surface for the 13 microphysical schemes. The main source of DLR at the surface is water vapour emission from the atmosphere while the highfrequency variations are due to the grey-body emission coming from the cloud base.

to water vapour emission and a fast-varying component due to cloud emission.

For each microphysical scheme we compute the time series of the mean DLR flux at the surface $\bar{F}_{\text {LW }}$ averaged over the domain as follows:

$\bar{F}_{\mathrm{LW}, t}=\sum_{i=1}^{N_{x}} \mathrm{GLW}_{i, t} / N_{x}$,

where GLW is the WRF output variable representing the downward longwave flux at the surface, while $i$ and $N_{x}$ are the spatial index and the number of cells along $x$ already introduced in Sect. 3.

In Fig. 9 it can be seen that $\bar{F}_{\text {LW }}$ is clearly characterized by the two components mentioned above: the slow-varying component due to water vapour and the fast-varying components due to clouds. The lines in this figure are similar, apart from the noise due to clouds, to the lines of WV in Fig. 4: $\mathrm{KS}$ is at the top and almost constant in time, WSM3 is at the bottom and characterized by a rapid decrease, and the rest of the schemes are in between and characterized by a decrease more similar to WSM3 than to KS. Even though WV is the mean column density of water vapour, it is still representative of the smaller amount of water vapour near the surface that emits the radiation absorbed by the ground because most of its mass is in the lower layers of the atmosphere. It is therefore reasonable to expect that higher (lower) amounts of $\mathrm{WV}$ correspond to higher (lower) values of $\bar{F}_{\mathrm{LW}}$.

All the schemes start with high values of $\bar{F}_{\text {LW }}$ between 361 and $366 \mathrm{~W} \mathrm{~m}^{-2}$, because of the high amounts of water vapour and clouds. During the first 10 days the average value of $\bar{F}_{\mathrm{LW}}$ is lowered between 307 (WSM3) and $342 \mathrm{~W} \mathrm{~m}^{-2}$
(KS), although there are strong oscillations with peaks above $350 \mathrm{~W} \mathrm{~m}^{-2}$. KS then stabilizes around $340 \mathrm{~W} \mathrm{~m}^{-2}$ until the end with oscillations as large as $17 \mathrm{~W} \mathrm{~m}^{-2}$ (day 40). WSM3 instead decreases rapidly until day 30 where it reaches a stable value until the end of about $257 \mathrm{~W} \mathrm{~m}^{-2}$ and has smaller oscillations, especially from day 15 to day 40. MY and MO have similar values for most of the simulation and decrease more slowly than the other schemes, reaching final values of around $289 \mathrm{~W} \mathrm{~m}^{-2}$. They exhibit strong oscillations in the first month which are reduced during the second month. SBU also reaches final values similar to MY and MO, however his trend is more unclear and it fluctuates between 280 and $300 \mathrm{~W} \mathrm{~m}^{-2}$ with a period of several days between day 35 and day 61 . The rest of the schemes decrease more regularly and stabilize around values between 260 and $280 \mathrm{~W} \mathrm{~m}^{-2}$ in the last 10 days. The average values in the last 10 days for $\mathrm{LN}$, WSM5, EM, WSM6, GM, NT, WDM5 and WDM6 are respectively 261, 264, 264, 260, 269, 278, 267 and $260 \mathrm{~W} \mathrm{~m}^{-2}$.

The microphysical schemes, by modifying the distribution of water vapour and clouds, strongly affect the DLR. In a more realistic simulation the choice of the microphysical scheme is important, as the DLR modifies the surface heat budget. Even excluding KS, in our idealized scenario we obtain, after the stabilization, scheme to scheme differences of up to $33 \mathrm{~W} \mathrm{~m}^{-2}$, which corresponds to about $10 \%$ of the global annual mean DLR of $342 \mathrm{~W} \mathrm{~m}^{-2}$ (Wild et al., 2013).

\subsection{Shortwave radiation}

As for GLW, we compute the average values over the domain of SWDOWN, the WRF variable which represents the downward shortwave radiation (DSR) flux at the surface, using the same notation of Eq. (8):

$\bar{F}_{\mathrm{SW}, t}=\sum_{i=1}^{N_{x}} \mathrm{SWDOWN}_{i, t} / N_{x}$.

The values of $\bar{F}_{\mathrm{SW}}$ are null before 06:00:00 LT and after 18:00:00 LT, because in those time intervals the Sun is not shining. Between 06:00:00 LT and 18:00:00 LT, $\bar{F}_{\text {SW }}$ increases to a maximum around noon and decreases again to zero before sunset. In order to more easily compare the time series of the microphysical schemes, we compute the daily average value of $\bar{F}_{\mathrm{SW}}$, naming it $\bar{F}_{\mathrm{SW}}^{\mathrm{d}}$, which is shown in Fig. 10.

KS starts with values of $\bar{F}_{\text {SW }}^{\text {d }}$ around $50 \mathrm{~W} \mathrm{~m}^{-2}$ and then increases slightly, oscillating between 50 and $100 \mathrm{~W} \mathrm{~m}^{-2}$. The other schemes start with higher values, between 90 and $243 \mathrm{~W} \mathrm{~m}^{-2}$, and increase as well. Their final values are however confined in a smaller range, between 247 and $295 \mathrm{~W} \mathrm{~m}^{-2}$. MY and MO, and partly SBU, are more distinguishable from the others because the differences in their average values are bigger than the day to day variations. Like for the longwave case, SBU is characterized by slower and 


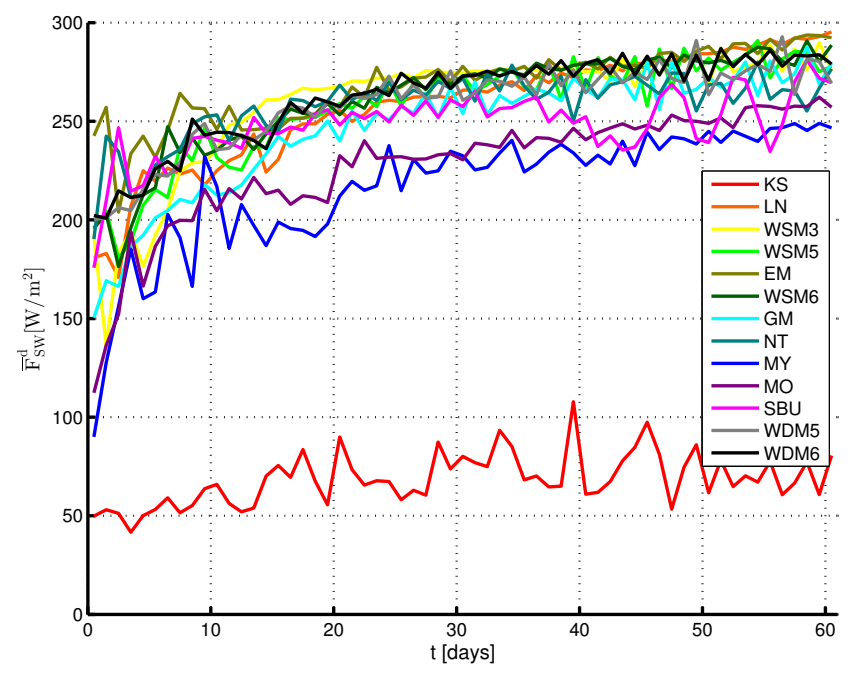

Fig. 10. Comparison of the daily averaged values of the mean DSR flux at the surface for the 13 microphysical schemes.

larger oscillations during the last 25 days of the simulation and it is in antiphase with $\bar{F}_{\text {LW }}$.

Excluding KS, the largest difference in the final values of $\bar{F}_{\mathrm{SW}}^{\mathrm{d}}$ is between LN and MY, which differ by about $49 \mathrm{~W} \mathrm{~m}^{-2}$. Such a discrepancy is quite high considering that the actual estimate for global mean shortwave flux absorbed by the surface is $161 \mathrm{~W} \mathrm{~m}^{-2}$ (Wild et al., 2013).

\section{Conclusions}

We studied the impact of microphysical parameterizations on the atmospheric water cycle using a simple idealized simulation. The numerical model used, the WRF model, contains several microphysics options and it is widely used by the research community to conduct RCM simulations. By using WRF v3.3.1, we tested 13 different microphysical schemes over a period of two months in a high resolution 2-D scenario of moist air flow over an idealized bell-shaped mountain. Lateral boundary conditions were set to be periodic so that we could check the conservation of water over a time interval of 61 days in the WRF simulations.

First, we analysed the total water content and concluded that, at least for the period under consideration, all the microphysical schemes conserve water. WDM5 was the scheme with the biggest loss of total water, with a final amount only $0.81 \%$ smaller than at the beginning. Considering that in a typical RCM simulation the lateral boundary conditions are updated every 6 or $12 \mathrm{~h}$, such a small loss is irrelevant.

We showed that, despite the same initial and boundary conditions and model configuration, the choice of the microphysical scheme has important consequences on different components of the water cycle, including water vapour, hydrometeors and accumulated precipitation. KS gave quite different results from the rest of the schemes, which is not surprising because it is the only scheme without ice-phase processes. The inclusion of ice processes is crucial to realistically represent clouds and the different types of precipitation. The other schemes, although more similar to each other, still showed important differences. In particular, by excluding KS, we have found that the final values obtained with different microphysics options, expressed as mean column densities averaged over the domain, can vary by up to $79 \%$ for water vapour, up to 10 times for hydrometeors and up to $64 \%$ for accumulated precipitation.

Furthermore, microphysics, by modifying the distribution of water vapour and hydrometeors, indirectly influences surface evaporation and downward radiation at the surface. We have found differences in surface evaporation of up to $84 \%$ (without considering KS).

For the downward radiation at the surface, we considered the longwave and the shortwave components separately. The simulated time series of the DLR contains the combined effects of the water vapour emission, which varies slowly, and the clouds emission, which is more variable in time. The same is true for the time series of the daily average DSR flux. KS has the highest value of DLR flux and the lowest value of DSR flux, because higher amounts of water vapour and clouds emit more infrared radiation and let less solar radiation pass through the atmosphere. The other schemes show differences in the final values of up to $33 \mathrm{~W} \mathrm{~m}^{-2}$ for the DLR flux and up to $49 \mathrm{~W} \mathrm{~m}^{-2}$ for the DSR flux.

It is important to note that the results we obtained for this particular model configuration are not universal. A different model setup with a different combination of physical parameterizations could lead to different results because the microphysics are influenced by the interactions with the other schemes. However, the wide range in terms of water phases, hydrometeor distributions and precipitation that we obtained suggests that any other combination of physical schemes might present a similar spread in the results for different microphysical schemes and that the choice of the microphysical scheme is a dominant factor in the performance of the model.

Acknowledgements. The study was mainly funded by the Oeschger Centre for Climate Change Research (University of Bern) and the MeteoSwiss project MIMAH of the Global Atmosphere Watch Programme. We are grateful to Niklaus Kämpfer, Christian Mätzler and Christoph Schär for advice and discussions. The authors would also like to thank all the WRF developers for providing the freely available numerical model that made this study possible.

Edited by: A. Lauer 


\section{References}

Argüeso, D., Hidalgo-Muñoz, J. M., Gámiz-Fortis, S. R., EstebanParra, M. J., Dudhia, J., and Castro-Díez, Y.: Evaluation of WRF Parameterizations for Climate Studies over Southern Spain Using a Multistep Regionalization, J. Climate, 24, 5633-5651, doi:10.1175/JCLI-D-11-00073.1, 2011.

Awan, N. K., Truhetz, H., and Gobiet, A.: Parameterization-Induced Error Characteristics of MM5 and WRF Operated in Climate Mode over the Alpine Region: An Ensemble-Based Analysis, J. Climate, 24, 3107-3123, doi:10.1175/2011JCLI3674.1, 2011.

Bellprat, O., Kotlarski, S., Lüthi, D., and Schär, C.: Objective calibration of regional climate models, J. Geophys. Res. Atmos., 117, D23115, doi:10.1029/2012JD018262, 2012.

Caldwell, P., Chin, H.-N. S., Bader, D. C., and Bala, G.: Evaluation of a WRF dynamical downscaling simulation over California, Climatic Change, 95, 499-521, doi:10.1007/s10584-009-95835, 2009.

Chahine, M. T.: The hydrological cycle and its influence on climate, Nature, 359, 373-380, 1992.

Chen, S.-H. and Lin, Y.-L.: Orographic effects on a conditionally unstable flow over an idealized three-dimensional mesoscale mountain, Meteorol. Atmos. Phys., 88, 1-21, doi:10.1007/s00703-003-0047-6, 2005.

Druyan, L. M., Fulakeza, M., Lonergan, P., and Noble, E.: Regional climate model simulation of the AMMA Special Observing Period \# 3 and the pre-Helene easterly wave, Meteorol. Atmos. Phys., 105, 191-210, doi:10.1007/s00703-009-0044-5, 2009.

Dudhia, J.: Numerical study of convection observed during the winter monsoon experiment using a mesoscale two-dimensional model, J. Atmos. Sci., 46, 3077-3107, doi:10.1175/15200469(1989)046<3077:NSOCOD>2.0.CO;2, 1989.

Fita, L., Fernández, J., and García-Díez, M.: CLWRF: WRF modifications for regional climate simulation under future scenarios, Poster at 11th WRF Users' Workshop in Boulder, 2010.

Gallus Jr., W. A. and Bresch, J. F.: Comparison of impacts of WRF dynamic core, physics package, and initial conditions on warm season rainfall forecasts, Mon. Weather Rev., 134, 2632-2641, doi:10.1175/MWR3198.1, 2006.

Givati, A., Lynn, B., Liu, Y., and Rimmer, A.: Using the WRF Model in an Operational Streamflow Forecast System for the Jordan River, J. Appl. Meteorol. Clim., 51, 285-299, doi:10.1175/JAMC-D-11-082.1, 2012.

Hocke, K., Kämpfer, N., Gerber, C., and Mätzler, C.: A complete long-term series of integrated water vapour from groundbased microwave radiometers, Int. J. Remote Sens., 32, 751-765, doi:10.1080/01431161.2010.517792, 2011.

Jankov, I., Gallus, W. A., Segal, M., Shaw, B., and Koch, S. E.: The Impact of Different WRF Model Physical Parameterizations and Their Interactions on Warm Season MCS Rainfall, Weather Forecast., 20, 1048-1060, doi:10.1175/WAF888.1, 2005.

Jankov, I., Bao, J.-W., Neiman, P. J., Schultz, P. J., Yuan, H., and White, A. B.: Evaluation and Comparison of Microphysical Algorithms in ARW-WRF Model Simulations of Atmospheric River Events Affecting the California Coast, J. Hydrometeorol., 10, 847-870, doi:10.1175/2009JHM1059.1, 2009.
Kessler, E.: On the distribution and continuity of water substance in atmospheric circulations, Vol. 32, American meteorological society, 1969.

Liang, X.-Z., Kunkel, K. E., Wilhelmson, R., Dudhia, J., and Wang, J. X. L.: The WRF Simulation of the 1993 Central U.S. Heavy Rain: Sensitivity to Cloud Microphysics Representation, in: 16th Conference on Hydrology, 2002.

Liang, X.-Z., Xu, M., Yuan, X., Ling, T., Choi, H. I., Zhang, F., Chen, L., Liu, S., Su, S., Qiao, F., He, Y., Wang, J. X. L., Kunkel, K. E., Gao, W., Joseph, E., Morris, V., Yu, T.-W., Dudhia, J., and Michalakes, J.: Regional Climate-Weather Research and Forecasting Model, B. Am. Meteorol. Soc., 93, 1363-1387, doi:10.1175/BAMS-D-11-00180.1, 2012.

Lin, Y., Farley, R., and Orville, H.: Bulk parameterization of the snow field in a cloud model, J. Clim. Appl. Meteorol., 22, 1065-1092, doi:10.1175/15200450(1983)022<1065:BPOTSF>2.0.CO;2, 1983.

Mercader, J., Codina, B., Sairouni, A., and Cunillera, J.: Results of the meteorological model WRF-ARW over Catalonia, using different parameterizations of convection and cloud microphysics, J. Weather Clim. West. Med., 7, 75-86, doi:10.3369/tethys.2010.7.07, 2010.

Miglietta, M. M. and Rotunno, R.: Simulations of Moist Nearly Neutral Flow over a Ridge, J. Atmos. Sci., 62, 1410-1427, doi:10.1175/JAS3410.1, 2005.

Miglietta, M. and Rotunno, R.: Further results on moist nearly neutral flow over a ridge, J. Atmos. Sci., 63, 2881-2897, doi:10.1175/JAS3793.1, 2006.

Mlawer, E. J., Taubman, S. J., Brown, P. D., Iacono, M. J., and Clough, S. A.: Radiative transfer for inhomogeneous atmospheres: RRTM, a validated correlated-k model for the longwave, J. Geophys. Res., 102, 16663-16682, doi:10.1029/97JD00237, 1997.

Otkin, J. A. and Greenwald, T. J.: Comparison of WRF ModelSimulated and MODIS-Derived Cloud Data, Mon. Weather Rev., 136, 1957-1970, doi:10.1175/2007MWR2293.1, 2008.

Pathirana, A., Herath, S., and Yamada, T.: Simulating orographic rainfall with a limited-area, non-hydrostatic atmospheric model under idealized forcing, Atmos. Chem. Phys., 5, 215-226, doi:10.5194/acp-5-215-2005, 2005.

Skamarock, W., Klemp, J., Dudhia, J., Gill, D., Barker, D., Duda, M., yu Huang, X., and Wang, W.: A Description of the Advanced Research WRF Version 3, Tech. rep., Mesoscale and Microscale Meteorology Division, National Center for Atmospheric Research, doi:10.5065/D68S4MVH, available at: http://nldr.library.ucar.edu/repository/collections/ TECH-NOTE-000-000-000-855 (last access: 13 December 2013), 2008.

Tulich, S. N., Kiladis, G. N., and Suzuki-Parker, A.: Convectively coupled Kelvin and easterly waves in a regional climate simulation of the tropics, Clim. Dynam., 36, 185-203, doi:10.1007/s00382-009-0697-2, 2011.

Wang, W., Bruyère, C., Duda, M., Dudhia, J., Gill, D., Lin, H.C., Michalakes, J., Rizvi, S., and Zhang, X.: Weather Research \& Forecasting ARW Version 3 Modeling System User's Guide, Mesoscale \& Microscale Meteorology Division, NCAR, 2012. 
Watson, C. D. and Lane, T. P.: Sensitivities of Orographic Precipitation to Terrain Geometry and Upstream Conditions in Idealized Simulations, J. Atmos. Sci., 69, 1208-1231, doi:10.1175/JAS-D11-0198.1, 2012.

Wild, M., Folini, D., Schär, C., Loeb, N., Dutton, E. G., and KönigLanglo, G.: The global energy balance from a surface perspective, Clim. Dynam., 40, 3107-3134, doi:10.1007/s00382-0121569-8, 2013.
Zhang, Y., Dulière, V., Mote, P. W., and Salathé, E. P.: Evaluation of WRF and HadRM Mesoscale Climate Simulations over the U.S. Pacific Northwest, J. Climate, 22, 5511-5526, doi:10.1175/2009JCLI2875.1, 2009. 